\title{
SENI PERTUNJUKAN CERITA SI PITUNG: PERTARUNGAN IDENTITAS DAN REPRESENTASI BUDAYA BETAWI
}

\author{
Siti Gomo Attas \\ Universitas Negeri Jakarta \\ tigo_attas@yahoo.co.id
}

\begin{abstract}
Abstrak
Tulisan ini bertujuan untuk menjelaskankan bagaimana cerita si Pitung diperebutkan oleh berbagai kekuatan sosial di luar dirinya dalam konteks representasi identitas budaya Betawi. Kontestasi kekuatan pertarungan antar kekuatan untuk memperebutkan cerita Si Pitung sebagai identitas merepresentasikan budaya Betawi. Melalui cerita si Pitung pertarungan identitas melalui mitos dapat memporakporandakan kekuatan kolonial, terutama kekuatan kontestasi antara budaya local dengan hegemoni colonial bahwa orang pribumi di dalam hal ini budaya Budaya orang Betawi adalah orang lemah, tertindas dan suka merampok. Penelitian ini akan membahas: (1) proses pertarungan dalam memaknai cerita si pitung antara masyarakat kolonial dan tuan tanah melawan masyarakat pribumi , (2) posisi kekuatan social yang ada dalam mewujudkan hegemoni atas cerita si Pitung dan perannya dalam pertarungan perebutan representasi identitas masyarakat Betawi. Sebagai sesuatu yang terbangun dari identitas merupakan sesuatu yang bersifat retak, dan berubah-rubah mengikuti ruang dan waktu. Representasi identitas cerita si Pitung merupakan medan pertarungan pemaknaan dalam lingkup kebudayaan.
\end{abstract}

Kata-kata kunci: cerita si Pitung, representasi, hegemoni, kontestasi dan identitas

\section{Pendahuluan}

Sejarah terbentuknya Jakarta dimulai ketika Belanda merebut kota Jayakarta dari dan mendirikan kota Batavia tahun 1619, sebagai pangkalan utama operasi mereka di Hindia Timur, daerah yang terletak di bagian tengah pantai utara Jawa Barat merupakan daerah yang jarang penduduknya dan diapit oleh dua kesultanan, yaitu Banten dan Ciribon. Namun, J.P. Coen tidak menarik orang jawa dari pedalaman sekitar dengan alasan keamanan. Justru J.P. Coen mendatangkan orang Tionghoa dan orang-orang Banda yang telah ditaklukkan untuk menetap di Batavia (Castle, 1967:6).

Secara historis sejak tahun 1673, 1815, 1893 nama Betawi belum ada dalam Dagh Register (Batavia, 1673) History of Jawa (Raffles, 1815) dan Encyclopedie van Nederlandsch Indie (1893) sebagai sebuah suku tersendiri. Menurut catatan Raffless bahwa sebagian besar penduduk yang memenuhi Batavia pada saat itu berasal dari Indonesia Timur. Penduduk Indonesia Timur ini menempati wilayah daerah pedalaman tepat di pinggir Batavia (Ommelanden). Jadi, dapat dipastikan bahwa sumbangsi 
terbesar dalam pembetukan suku baru yang disebut Betawi, yang muncul berdasarkan data Sensus Penduduk tahun 1930 berasal dari Indonesia Timur (Castel, 1967:11).

Pembentukan suku baru yang dikenal dengan suku Betawi berasal dari peleburan suku bangsa yang ada berdasarkan catatan Raffles dkk. bahwa pada saat itu telah terjadi melting pot (panci pelebur) secara perlahan-lahan telah mengikis penduduk yang beridentitas ganda menjadi sebuah identitas baru yang disebut Betawi. Menurut hasil penelitian Raben (1999) sejarah asal-usul etnis Betawi, juga telah dibahas oleh para pakar yang mengaitkan dengan pertumbuhan dan perkembangan penduduk kota Batavia berdasarkan pada arsip pemerintah Kolonial Belanda. Lance Castle (1967), Edisi Bahasa Indonesia terjemahan Gatot Triwira 2007, hlm. 10-12), mengemukakan bahwa berdasarkan pencatatan penduduk di Batavia tahun 1673, 1815, dan 1893 menunjukkan sejak 1673 dan 1815 jumlah penduduk dikelompokkan berdasarkan etnis. Berdasarkan informasi Raffles pada tahun 1815 sebagian penduduk Batavia itu adalah budak yang berasal dari Bali dan Sulawesi Selatan. Suku Betawi berdasarkan data di atas bahwa Betawi terbentuk dari berbagai suku dan etnis Nusantara yang mayoritas berasal dari Indonesia Timur. Di pihak lain, kebudayaan yang turut membentuk suku baru itu, yaitu Islam dan bahasa Melayu yang berasal dari Indonesia Barat. Jadi, dapat dimungkinkan bahwa terbentuknya suku Betawi di Batavia melalui proses peleburan atau melting pot.

Namun menurut sejarawan Sagiman MD, bahwa eksistensi suku Betawi telah ada serta mendiami Jakarta dan sekitarnya sejak zaman batu baru atau pada zaman neolitikum. Penduduk asli Betawi adalah penduduk Nusa Jawa sebagaimana orang Sunda, Jawa, dan Madura (Suku Betawi, (2014). Berdasarkan data Arkeolog Uka Tjandarasasmita (dalam Knoerr, 2002, hlm. 203-221) menunjukkan data arkeologis bahwa "terdapat bukti-bukti yang kuat dan ilmiah tentang sejarah penghuni Jakarta dan sekitarnya dari masa sebelum Tarumanagara di abad ke-5." Dikemukakan bahwa paling tidak sejak zaman neolitikum atau batu baru (3500-3000 tahun yang lalu) bahwa beberapa tempat yang diyakini telah memiliki penghuni, yaitu Cengkareng, Sunter, Cilincing, Kebon Sirih, Tanah Abang, Rawa Belong, Sukabumi, Kebon Nanas, Jatinegara, Cawang, Cililitan, Kramat Jati, Condet, Pasar Minggu, Pondok Gede, Tanjung Barat, Lenteng Agung, Kelapa Dua, Cipete, Pasar Jumat, Karang Tengah, Ciputat, Pondok Cabe, Cipayung, dan Serpong. Penandaan akan adanya kehidupan pada amsa itu, yaitu: kapak, beliung, pahat, pacul yang sudah diumpam halus dan memakai gagang dari kayu, disimpulkan bahwa masyarakat manusia itu sudah mengenal pertanian.

Sebutan suku, orang, dan kaum Betawi, menurut laporan Van der Aa (1846 dalam Shahab, 2004, hlm. 4 dan Chaer, 2012, hlm. 6) muncul dan mulai populer ketika Mohammad Husni Tamrin mendirikan perkumpulan "Persatoean Kaoem Betawi" pada tahun 1923 dan ikut serta dalam semangat Sumpah Pemuda dan Kongres Pemuda II tahun 1928. Meski ketika itu penduduk asli belum dinamakan Betawi, tapi Kota Batavia disebut "negeri" Betawi sebagai kategori "suku" dimunculkan dalam sensus 
penduduk tahun 1930. Seiring dengan kedudukan suku Betawi berdasarkan data sensus penduduk 1930 (Castle, 1967) maka dapat dipastikan suku Betawi ada di Batavia berasal dari proses melting pot (panic peleburan)

Selanjutnya latar social histori terjadinya cerita rakyat di Batavia dikaitkan dengan kekuasaan VOC (Vereenigde Oost Indische Compagnie) tahun 1602 (Moedjanto, 1988:16). Keberadaan VOC yang mendapat hak kedaulatan, yaitu : (1) hak mengadakan perjanjian dengan Negara-begara lain, (2) Hak memmerintah daerah di luar negeri Belanda termasuk mendirikan daerah- daerah di luar negeri belanda, (3) hak memebtuk tentara dan mendirikan benteng, (4) hak mengeluarkan mata uang dan mengedarkannya. Selanjutnya VOc juga mendapat hal istimewa, yaitu : (1) hak monopoli dagang, (2) hak menyerahkan produksinya kepada pribumi, (3) menempati tempat strategis dan campur tangan dengan raja-raja di luar Batavia, (5) hak campur tangan VOC terhadap kerajaan-kerajaan di Indonesia terbatas pada usaha-usaha mengumpulkan hasil bumi dan pelaksanaan monopoli, misalnya dengan pelayaran hongi, hak ekstirpasi, yaitu hak untuk melakukan penebangan pohon-pohon produksi untukk pasar Eropa agar harga tidak menurun untuk produksi yang berlebihan., (5) VOC menggunakan alat tukar barang karena masih terbatasnya penggunaan uang.

Hak istimewa VOC ini juga dipergunakan oleh Belanda pada saat VOC mengalahkan kerajaan Sunda Kelapa yang dipimpin oleh Pangeran Jayakarta, seluruh tanah milik kerajaan itu dianggap sebagai milik VOC. Pada tahun-tahun pertama kekuasaan VOC di Batavia, Belanda sudah menjuali tanah miliknya kepada orang-orang Eropa, Cina, dan Arab. Dari sinilah maka dimulainya berlaku Tanah partikulir/Particuliere Landerijn) para penyewa tanah partikulir umumnya dalah penduduk pribumi (termasuk orang Betawi). Kaum pribumi memiliki hak yang sangat lemah nyaris mendekati budak belian. Hal ini, disebabkan oleh tidak adanya perlindungan hukum penyewaan yang jelas (Kartodirdjo, 1973:21)

Berdasarkan danpak dari penindasan yang dilakukan oleh pemilik tanah kepada para penggarap, yaitu orang pribumi termasuk masyarakat Betawi telah mendatangkan kemiskinan dan ketakutan rakyat kepada pemerintah Belanda dan para pemilik tanah atau tuan-tuan tanah. Gambaran inilah yang mendatangkan beberapa pembrontakan yang dipimpin oleh para jagoan dari kalangan pribumi untuk melakukan perlawanan melawan kesewenagan tersebut. Munculnya tokoh-tokoh jagoan di Betawi pada saat itu sebagai bentuk perlawanan. Munculnya tokoh jagoan yang memiliki ilmu bela diri dan telah melakukan keonaran di Batavia telah menjadi cerita lisan bagi masyarakat untuk meredam kekuatan Belanda dan para kaki tangannya untuk mengeksploitasi rakyat.

Kemunculan tokoh jagoan ini dapat dibagi dalam dua tipe, yaitu jagoan yang alim dan jagoan dengan tipe Bengal. Menurut Ridwan Saidi (1997:87) bahwa sislsilah jagoan Betawi yang ditulis dalam makalah ini dimulai pada akhir abad ke-19 M. jagoaan Betawi dari Kampung Kemayorann diwakili oleh Murtado adalah tipe jagoan yang alim. Sementara itu jagoan yang Bengal yang juga dikenal sebagai 
tokoh jagoan yang legendaris, yaitu tokoh si Pitung. Sebelum muncul tokoh si Pitung ada tokoh si Puasa a(Kuasa) dari kampong Kwitang. Selanjutnya tokoh jagoan Murtado dilanjutkan oleh tokoh oleh jagoan Ja'man dan Haji entong Gendut dari Condet yang wafat tahun 1916 dalam pertempuran melawan belanda. Munculnya cerita jagoan ini ini adalah sebagai penetrasi budaya yang dilakukan para seniman untuk bisa menyampaikan pesan secara berkesenian, baik melalui pertunjukan atau melalui cerita rakyat, atau cerita rakyat yang dipertunjukan seperti pertunjukan gambang rancag di masyarakat Betawi yang diadakan jika ada pesta rakyat atau tanggapan pesta dari masyarakat.

\section{Metodologi Penelitian}

Sumber data dari penelitian ini adalaah cerita si Pitung, sebuah cerita lisan yang melegenda di Batavia pada jamannya. Analisis data dengan teknik deskriptif kualitatif. Dalam penelitian ini kesahihan yang digunakan yaitu dengan menggunakan kajian budaya dan sejarah, yaitu pada teori poststrukturalis dengan menggunakan oposisi biner. Bahwa representasi dipakai perspektif poststrukturame dan teori postkolonial, pendekatan cultural studies memposisikan pengetahuan bukan sebagai suatu kebenaran obyektif, melainkan sebagai suatu produk kita mengkategorisasikan dunia melalui

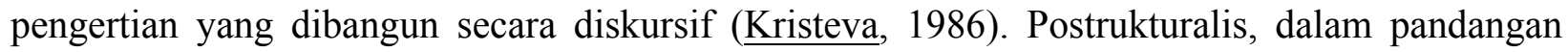
Michel Foucault melihat pengetahuan lahir dari suatu proses diskursif.

\section{Pembahasan}

Untuk melihat gambaran representasi seni pertunjukan cerita si Pitung melalui pertarungan identitas dan representasi budaya Betawi terlebih dahulu harus membaca cerita si Pitung versi masyarakat Betawi menurut Koesasi (1992) bahwa Si Pitung adalah salah satu pendekar betawi berasal dari kampung Rawabelong Jakarta Barat. Selain itu Si Pitung menggambarkan sosok pendekar yang suka membela kebenaran dalam menghadapi ketidakadilan yang ditimbulkan oleh penguasa Hindia Belanda pada masa itu. Kisah pendekar Si Pitung ini diyakini nyata keberadaannya oleh para tokoh masyarakat Betawi terutama di daerah Kampung Marunda di mana terdapat Rumah dan Masjid lama.

Diceritakan bahwa Si Pitung lahir di daerah Pengumben, di sebuah kampung di Rawabelong yang pada saat ini berada di sekitar lokasi Stasiun Kereta Api Palmerah. Ayahnya bernama Bang Piung dan ibunya bernama Mpok Pinah. Pitung menerima pendidikan di pesantren yang dipimpin oleh Haji Naipin, seorang pedagang kambing. Si Pitung merupakan nama panggilan asal kata dari bahasa Sunda pitulung (minta tolong atau penolong). Kemudian, nama panggilan ini menjadi Pitung. Nama asli si Pitung sendiri adalah Salihun (Salihoen). Pada dasarnya ada tiga versi yang tersebar di masyarakat mengenai si Pitung yaitu versi Indonesia, Belanda, dan Cina. Masing-masing penutur versi cerita tersebut memiliki versi 
yang berbeda dari cerita si Pitung itu sendiri. Apakah si Pitung sebagai seorang pahlawan berdasarkan versi cerita Indonesia dan Cina, dan sebagai seorang penjahat jika dilihat dari versi Belanda. Cerita si Pitung ini dituturkan oleh masyarakat Indonesia hingga saat ini dan menjadi bagian legenda serta warisan budaya Betawi khususnya dan Indonesia umumnya. Kisah legenda Si Pitung ini kadang-kadang dituturkan menjadi rancak (sejenis balada), sair, atau cerita Lenong. Menurut versi Koesasi (1992), Si Pitung diidentikan dengan tokoh Betawi yang membumi, muslim yang shaleh, dan menjadi contoh suatu keadilan sosial.

Dari perspektif poststrukturame dan teori postkolonial, pendekatan cultural studies memposisikan pengetahuan bukan sebagai suatu kebenaran obyektif, melainkan sebagai suatu produk kita mengkategorisasikan dunia melalui pengertian yang dibangun secara diskursif. Menurut Foucault, pengetahuan berkenaan pula dengan relasi kekuasaan, seperti yang dikatakannya : " Power produces knowledge, in the sense that what is considered 'true', knowledge about a topic is constructed through discourse. It is discursive knowledge which has the power to make itself true" ( Stuart Hall, 1997: 49). Jadi, dalam pengertian ini, kekuasan telah menciptakan pengetahuan mengenai apa yang kita anggap sebagai suatu "kebenaran", pengetahuan dikonstruksikan melalui wacana yang kemudian secara diskursif telah menciptakan kekuasan untuk menjadikannya sebagai kebenaran. Foucault kemudian melanjutkan analisisnya mengenai relasi antara pengetahuan dan kekuasaan sebagai berikut : "Knowledge produced by discourse is a kind of power because 'those who known in a particular way will be subject (i.e. subjected) to it “ ( Stuart Hall, 1997 : 295). Konstruksi sosial dalam pandangan postrukturalis menurut Foucault ini telah memberi pengaruh yang besar dalam analisis konteks yang secara spesifik melatarbelakangi suatu wacana dan terutama relasi yang dinamis antara pengetahuan dan kekuasaan. Pengetahuan bukan hanya diciptakaan melalui relasi kekuasaan tetapi juga melahirkan bentuk kekuasaan baru.

Sesuai dengan gambaran cerita si Pitung versi masyarakat Betawi bahwa Pitung adalah pahlawan. Penggambaran ini sebagai bentuk ekspresi yang dikomunikasikan oleh masyarakat Betawi melauli ide, konsep dan perasaan kita yang merupakan transmisi makna berupa informasi. dalam bentuk pengetahuan yang disampaikan melalui cerita rakyat, dan pengetahuan itu dianggap sebagai sebuah kebenaran. Keberan ini terlihat dari begitu melegendanya cerita si Pitung di kalangan msyarakat Betawi dibanding tokoh-tokoh lain yang juga hadir dalam cerita jagoan Betawi. Kekuasan telah menciptakan pengetahuan mengenai apa yang kita anggap sebagai suatu "kebenaran", Bahwa wacana yang muncul sebagai cerita rakyat Si Pitung yang 
secara diskursif telah menciptakan anggapan bahwa masyarakat Betawi adalah masyarakat kuat, bukan masyarakat yang lemah seperti yang selama ini berlangsung sebagai msyarakat yang inferior, msyarakat tertindas. Dengan hadirnya cerita si Pitung dapat mengubah paradigm masyarakat Betawi bahwa mereka kini telah memiliki jago yang dapat mengalahkan pihak Belanda. Beberapa kali si Pitung lolos dari kejaran Belanda. Pitung berhasil memperdayai pihak Belanda. Dalam hal ini masyarakat Betawi telah berhasil menciptakan kekuasaan melalui wacana cerita si Pitung, yaitu membalik anggapan yang semula lemah menjadi masyarakat yang kuat, tidak lemah lagi tapi kini memiliki kekuatan untuk bisa melawan Belanda seperti yang dilakukan si Pitung.

Sementara cerita si Pitung menurut versi van Till (1996) si Pitung merupakan seorang kriminal, diawali ketika si Pitung menjual kambing di pasar Tanah Abang yang kemudian dicuri oleh para "centeng" (Si Gomar menurut versi Film Si Pitung (1970) tuan tanah.Si Pitung kembali pulang dengan tangan hampa, namun si Pitung hanya tersenyum dan menjawab bahwa dia telah dirampok. Ayah Pitung yang marah kemudian menyuruh Pitung pergi mencari uang tersebut dan akhirnya dapat menemukannya kembali. Namun, para pencuri alias "centeng" tersebut mengajak Pitung untuk bergabung sebagai perampok dan menjadi ketua mereka. Pada awalnya Pitung menolak, tetapi akhirnya Pitung bergabung dengan mereka. Legenda yang dikisahkan dalam film Si Pitung, Pitung dan kawanannya menggunakan cara yang "pintar" dengan menyamar sebagai pegawai Pemerintah Belanda (Di Versi Film Si Pitung, Pitung disebut sebagai "Demang Mester Cornelis"-Wilayah Mester Cornelis saat ini disebut sebagai Jatinegara, merupakan bagian dari Kota Jakarta Timur-dan Dji-ih sebagai "Opas"). Kemudian, mereka melakukan penipuan dengan memberikan surat kepada Haji Saipudin agar Haji Saipudin menyimpan uang di tempat Demang Mester Cornelis. Pitung menyatakan bahwa uang tersebut dalam pengawasan pencurian. Haji Saipudin setuju kemudian Pitung dan Kelompoknya membawa lari uang tersebut.

Akibat dari hal ini, si Pitung dan kawanannya menjadi buronan "kompenie". Hal ini menarik perhatian komisaris polisi yang bernama Van Heyne (Schout Van Heyne, Van Heijna, Scothena, atau Tuan Sekotena). Secara resmi, menurut Van Till (1996), nama petugas polisi tersebut bernama A.W. Van Hinne yang pernah bertugas di Batavia dari tahun 1888 - 1912. Menurut catatan kepolisian Belanda, Van Hinne memulai karier sebagai pegawai klerikal Pemerintah Belanda, kemudian menjadi Deputi Kehutanan, dan Polisi di beragam tempat di Indonesia. Van Hinne menderita sakit yang serius sesudah dikembalikan ke Eropa untuk penyembuhan. Pada akhir tahun 1880, Van Hinne menjadi seorang Perwira Polisi di Batavia (Stambock van Burgerlijke Ambtenaren in Nederlandsch-Indie en Gouvernements Marine, ARA (Aigemeen Rijksarchief), Den Haag, register T.f. 274). Van Hinne segera memburu Si Pitung dengan membabi buta. Akhirnya dia dapat menangkap Pitung, tetapi kemudian Si Pitung berhasil 
melarikan diri dari tahanan ka-Demangan Meester Cornelis. Van Till (1996) menyatakan bahwa Si Pitung mampu bebas dengan kekuatan sihir, tetapi menurut versi Film Si Pitung (1970), Si Pitung lepas dengan menggunakan kekuatan tenaga dalam. Kemudian, Hinne menekan Haji Naipin (Guru Si Pitung) untuk membuka rahasia kesaktian si Pitung. Akhirnya, diketahui kesaktian tersebut berupa “jimat", sehingga Hinne dapat menangkap Si Pitung secara lebih cepat. Versi lainya menyatakan bahwa Pitung dikhianati oleh temannya sendiri (kecuali Dji-ih) walaupun versi ini diragukan kebenarannya. Tetapi menurut versi film Si Pitung Banteng Betawi (1971), ia dikhianati oleh Somad yang memberitahukan kelemahan Pitung untuk mengambil "jimatnya". Kisah lainnya menyatakan bahwa Pitung telah diambil "Jimat Keris"-nya sehingga kesaktiannya menjadi lemah. Versi lainnya mengatakan bahwa kesaktian Pitung hilang setelah dipotong rambut, dan juga versi lain mengatakan bahwa kesaktiannya hilang karena sesorang melemparkan telur. Akhirnya Pitung meninggal karena luka tembak Hinne (Berdasarkan versi Film Si Pitung, Pitung mati tertembak karena peluru emas). Sesudah Si Pitung meninggal, makamnya dijaga oleh tentara karena percaya bahwa Si Pitung akan bangkit dari kubur. Hal ini tersirat dari Rancak Si Pitung dalam Van Till (1996):

Relasi antara Pengetahuan dan Kekuasaan dalam cerita Si Pitung. Menurut Foukault bahwa melalui kekuasaan masyarakat Pribumi telah mnegkonstruksi cerita si Pitung yang direpresentasikan sebagai sebuah kebenaran. Hal ini disebakan oleh adanya persamaan nasib orang pribumi yang telah lama tertindas oleh kuasa pemerintah belanda dan tuan tanah di atas tanah partikulir. Cerita si Pitung dikonstruksi sebagai pahlawan. Tokoh si Pitung dari Rawa Belong diceritakan sebagai tokoh yang sejak kecil telah belajar agama dan ilmu bela diri. Pada suatu ketika Si Pitung di rampok sepulang dari menjual kambing gurunya. Sebagai rasa tanggung jawa Pitung pergi mencari si perampok dan akhirnya si Pitung diminta jadi ketua perampok oleh para buron.

Sepak terjang si Pitung telah membuat para Tuan tanah dan pemerintah Belanda kewalahan dan takut menghadapi si Pitung. Pitung merampok tuan tanah dan kaki tangan Belanda. Diceritakan dengan menyamar sebagai pegawai Belanda Pitung dan kawan-kawannya berhasil merampok Tuan Syaifuddin juragan perahu di Marunda. Hasil rampokannya banyak di berikan kepada rakyat, terutama yang telah lama menderita oleh ulah tuan tanah dan penguasa belanda. Hadirnya cerita si Pitung sebagai arus balik perlawanan rakyat yang memberi dukungan kepada Pitungdalam buronnya di beberapa tempat di wilayah Batavia.

Perlawanan Pitung melalui aksi perampokan kepada orang-orang tertentu telah membuat para kaki tangan dan penguasa Belanda ketakutan. Maka untuk menghadapi keganasan kelompok si Pitung melalui anggota polisi Belanda A.W.V. Hinne dan beberapa asistennya berhasil membunuh si Pitung dengan akal licik mereka dengan cara mnyogok beberapa orang pribumi agar bisa memperdayai Pitung. Sampai akhir hayatnya tokoh ini tetap menjadi buah bibir masyarakat. Bahwa Pitung hidup kembali 
karena kekuatan ilmu rawa rontek yang dimilikinya . Cerita berkembang dalam masyarakat bahwa mayat si Pitung harus dibagi dalam beberapa bagian, ada yang dikubur di jalan Palmerah tapi ada juga yang dikubur di gedung Telkom. Beberapa versi tentang kematian si Pitung ini juga sebagai bentuk perlawaman masyarakat Betawi untuk meredam bentuk semena-men Belanda dan tuan tanah kepada para rakyat Betawi.

Cerita Si Pitung versi Belanda, melalui tulisan Van Tiiil (1996) bahwa si Pitung adalah cerita yang difilmkan pada masa kolonial Belanda (1931) film ini disutradarai oleh Wong Bersaudara dan dibintangi oleh Herman Shim dan Ining Resmini. Film ini menceritakan Bandit si Pitung di Batavia. Tokoh bersejarah Si Pitung adalah seorang bandit abad ke-19 di Batavia, Hindia Belanda (sekarang Jakarta). Ia mengawali karier kriminalnya pada tahun 1892 dengan merampok Hadji Sapiudin, seorang tuan tanah kaya yang tinggal di timur laut Batavia. Sejak itu, Pitung terus mencuri, namun sejumlah orang mengatakan bahwa ia hanya mencuri dari orang-orang yang bekerja sama dengan pemerintah kolonial Belanda. Ia akhirnya ditangkap dalam sebuah sergapan dan dibunuh oleh petugas polisi A.W.V. Hinne dan beberapa asistennya.

Cerita si Pitung bagi masyarakat Betawi menurut sejarah direpresentasikan melalui cerita yang dikonstruksi oleh dua kekuatan. Kekuatan orang Pribumi dan kekuatan Belanda. Konstruksi orang Betawi tentang cerita si pitung adalah bentuk perlawanan dari kesewenang-wenangan kolonial Belanda dan tuan tanah. Cerita digambarkan bahwa Pitung adalah pahlawan yang melakukan perampokan terhadap orang-orang Belanda dan para tuan tanah. Hasil rampokaknnya dibagikan kepada rakyat. Danpak dari tindakan Pitung ini telah meresahkan orang Belanda dan para kaki tangannya. Mereka diliputi rasa takut akan kedatangan Pitung ke rumah mereka. Berbagai cara telah dilakukan oleh Belanda untuk bisa menangkap si Pitung yang sulit diketahui keberadaanya. Informasi dari masyarakat tentang keberadaan si Pitung hampir hilang ditelan bumi, tidak ada yang berani buka mulut akan keberadaan si Pitung. Cerita di Masyarakat mulai muncul bahwa Pitung memiliki dapat menghilang dan kebal terhadap bacokan dan peluru. Cerita ini tambah meresahkan orang Belanda, berbagai cara di cari oleh mereka agar dapat menangkap si Pitung. Kepala Polisi terbaik Belanda Schoot Hena ditugaskan untuk bisa menangkap Pitung hidup atau mati. Cerita mengenai kekuatan si Pitung telah membawa Schoot Hena hampir putus asah menjalankan tugas menangkap Pitung yang begitu licin dan gelap. Pada aakhirnya dengan bantuan orang bayaran maka informasi si Pitung dapat diketahui dan akhirnya Pitung mati ditembak oleh Schoot Hena. Mayatnya dipotong-potong karena ditajutkan Pitung bisa kembali. Bentuk perlawanan si Pitung ini adalah sebagai reperesentasi masyarakat Betawi melalui cerita jagoan si Pitung yang telah berani melawan Belanda dengan cara melakukan perampokan. Tokoh ini menjadi idola bagi masyarakat Betawi akan keberanian dan kebaikan si Pitung kepada rakyat. 
Sementara representasi cerita si Pitung versi Belanda, Pitung adalah bandit atau penjahat yang harus di penjara dan digantung. Cerita dikonstruksi dengan sudut pandang tokoh sebagai antagonis yang harus di tangkap karena untuk mempertanggungjawabkan semua perbuatannya. Cerita ini adalah bentuk kekuatan pemerintah belanda melalui berita surat kabar mengenai Pitung yang jahat dan tak kenal kasihan kepada orang yang dirampoknya. Sifat bandit yang dilekatkan oleh berita Belanda tentu dua hal yang berbeda dalam wacana yang samapai ke masyarakat saat itu. Menurut versi Belanda si Pitung tidak boleh dilindungi karena telah meresahkan masyarakat. Maka siapa saja yang melihat Pitung harus melaporkan kepada petugas karena Pitung adalah penjahat. Wacana itu dikonstruksi atas dasar kekuatan Belanda yang memiliki media saat itu, yaitu surat kabar Hindia Belanda. Berita bahwa Pitung bandit harus dihukum dan gantung. Pitung harus menerima resiko semua perbuatannya. Maka Schoot Hena sebagai pahlawan orang Belanda karena telah menembak mati si Pitung. Schoot hena diberi tanda jasa diadakan pesta atas keberhasilan menembak Pitung.

Kedua versi cerita yang berkembang di masyarakat sebagai dua kekuatan yang dioposisikan. Peratama Pitung adalah pahlawan orang Betawi sementara pihak Belanda menganggap bahwa Pitung adalah bandit tokoh antagonis. Sementara dua kekuatan ini saling beroposisi untuk meletakan sebuah kebenaran dari dua perspektif. Pemerintah Belanda sebagai pemegang kekuasaan penuh terhadap hidup orang pribumi lebih leluasa menekan orang pribumi bahwa yang benar adalah hokum Belanda bahwa Pitung bersalah sebagai bandit perampok yang harus dihukum. Sementara Rakyar Betawi memiliki kekuatan senasib dan sepenanggunagan memiiliki kekuatan untuk terus menghembuskan cerita si Pitung dengan berbagai mitos yang dipercayai oleh masyarakat akan ilmu si Pitung yang tinggi tidak mungkin bisa dilawan oleh Belanda.

\section{Simpulan}

Simpulan dari penelitian memaparkan representasi cerita rakyat melalui dua kekutan sebagai bentuk identitas masyarakat Betawi yang diwakili oleh versi cerita si Pitung dari masyarakat betawi, dan identitas Belanda dari kekuatan penguasa. Ada dua hal versi cerita yang dilihat berdasarkan dua versi cerita, yaitu:

1. Cerita si Pitung versi masyarakat Betawi yang menggambarkan adanya identitas kesamaan nasib dan sepenanggungan, berdasarkan perspektif sejarah diketahui bahwa masyarakat betawi dengan ketertindasan memunculkan cerita si Pitung sebagai pahlawan orang Betawi.

2. cerita si Pitung versi Belanda yang digambarkan karena adanya kekuatan sebagai penguasa dan penentu hokum yang berlaku di masyarakat Batavia saat itu menggambarkan bahwa Pitung adalah bandit, tokoh antagonis yang harus diyahan dan hokum mati. 
Representasi cerita si Pitung ini menandakan adanya sebuah kekuatan yang dimiliki oleh sebuah pengirim informasi berupa cerita yang duangggap sebagai sebuah kebenaran.

\section{DAFTAR PUSTAKA}

Attas,S. G. (2013). Restorasi kultural terhadap cerita rakyat mengenang Si Pitung sebagai kearifan lokal Betawi. Dalam:Makalah Seminar Foklor Asia. Yogyakarta: Panitia Kongres Internasional Folklor Asia III.

Braginsky, V.I. (1998). Yang Indah, Berfaedah, dan Kamal: Sejarah Sastra Melayu. Jakarta: INIS.

Channiago, Edwar. (2006). Luambek dan Randai di Minangkabau: Pengelolaan Seni Pertunjukan dalam Konteks Adat (dalam Telisik Tradisi). Jennifer Lindsay (penyunting). Jakarta:Kelola.

Castle, L. (1967). “The Etnnic Profile of Jakarta,” Indonesia, Vol III (April). Ithaca-New-York Cornel University.

Chaer, A. (2012). Folklor Betawi: Kebudayaan dan Kehidupan Orang Betawi. Jakarta: Masup Jakarta.

Djamaris, et al (1985). Antologi Sastra Indonesia Lama Pengaruh Islam. Jakarta: Pusat Pembinaan dan Pengembangan Bahasa, Departemen Pendidikan dan Kebudayaan.

Heukeun, A. SJ. (2000). Historical Sites of Jakarta. Jakarta: Cipta Loka Caraka.

JJ. Rizal.( 2009). Siapa dan Darimanakah Orang Betawi. ttps://staff.blog.ui.ac.id/syam-mb/2009/05/18/siapa-dan-darimanakahorang-betawi/. (DiaksesRabu, 6 Agustus 2009).

Kleden, N. (1987). Teater topeng Betawi sebagai teks dan maknanya suatu terapan antropologi. (Disertasi). Fakultas Ilmu Sosial dan Ilmu Politik, Universitas Indonesia, Depok.

Koesasi, B.(1992). Lenong dan Si Pitung. (Disertasi). Centre of Southeast Studies, Australian National University.

Koster, G.L.. 1997. Roaming through Seductive Gardens. Leiden: KITLV Press.

Kiftiawati. 9 Maret 2011. "Bertahan dalam Teriknya Zaman Nyi Meh, Kembang Topeng Betawi”. http://langgambudaya.ui.ac.id/betawi/artikel/detail/14/bertahan-dalam-teriknya-zaman/. (5 Maret 2013).

Kemendikbud.2009. Peraturan Pemerintah No.42 Tahun 2009 tentang Pedoman Pelestarian Kebudayaan. Jakarta: Depdiknas. 
Meindartato,W.(2009). Teori formula dalam tradisi lisan pantun Betawi. Jurnal Swara di Malaysia.hlm.

Muhadjir, dkk. (1986). Peta Seni Budaya Betawi. Jakarta: Dinas Kebudayaan DKI Jakarta.

Ong, W. J. (1988). Orality and Literacy: The Technologizing of the Word. London: Methuen.

Palupi, D. (1993). Cerita Si Pitung sebagai sastra lisan: analisis terhadap struktur cerita.(Tesis). Fakultas Sastra Universitas Indonesia, Depok.

Pudentia dan Effedi. (1996). Sekitar Penelitian Tradisi Lisan. Warta ATL. Edisi 11/Maret.

Ruchiat, R. (1981). Pendekatan sejarahdan latar belakang sosial budaya gambang rancag. Proyek Konservasi Kesenian Tradisional Betawi Dinas Kebudayaan Daerah Khusus Ibukota Jakarta, hlm. 3.

Ruchiat, dkk. (2003). Ikhtisar Kesenian Betawi. Jakarta: Dinas Kebudayaan dan Permusiuman Provinsi DKI Jakarta.

Rusyana, Y. (1978). Cerita rakyat Cirebon tentang penyebaran Islam.Himpunan Makalah tentang Cerita Rakyat. Bandung: FKSS IKIP.

Rusyana, Y. (1981). Cerita rakyat nusantara. Himpunan Makalah tentang Cerita Rakyat. Bandung: FKSS IKIP.

Spradley, James P. 2007. Metode Etnografi, Yogyakarta: Tiara Wacana.

Saidi, R. (1997). Profil Orang Betawi. Jakarta: PT Gunara Kata.

Saidi, R. (1997). Warisan Budaya Betawi. Jakarta: LSIP dan Pemda DKI Jakarta.

Sipardjo, Sriyono, 1981. Gambang Rancag. Jakarta: Dinas Kebudayaan DKI Jakarta

Saidi, R. (2010). Sejarah Jakarta dan Peradaban Melayu Betawi.Jakarta: Perkumpulan Renaisance Indonesia.

Saputra, Y.A. dan Nurzain. (2009). Profil Seni Budaya Betawi. Jakarta: Jakarta City Goverment Tourism dan Culture Office.

Shahab, Y. Z. (2012). Reproduksi dan revalitas kebudayaan Betawi: tantangan dan kesempatan dalam era nasionalisasi dan globalisasi. Festival Seni Budaya Betawi, Dinas Pariwisata dan Kebudayaan Provinsi DKI Jakarta, Minggu 2 Desember 2012, Setu Babakan.

Simatupang, L. (2013). Pergelaran Sebuah Mozaik Penelitian Seni-Budaya. Yogjakarta:Jalasutra.

Sopandi, Atik dkk. (1992). Gambang Rancag. Jakarta: Dinas Kebudayaan DKI Jakarta. 
Sweeney, A. (1987). A Full Hearing Orality and Literacy in The Malay World. Berkley: University of California Press.

Sibarani, Robert. (2012). Kearifan Lokal: Hakikat ,Peran, dan Metode Tradisi Lisan. Jakarta: Asosiasi Tradisi Lisan (ATL.

Murgianto, Sal. 2008. Mengenai Kajian Pertunjukan. Dalam Pudentia MPSS, (Penyunting) Metodologi Kajian Tradisi Lisan (hlm. 5-32). Jakarta: Asosiasi Tradisi Lisan (ATL).

van Till, Margaret (1996). In search of Si Pitung: the history of an Indonesian legend. Bijdragen tot de Taal-, Land- en Volkenkunde 152, no: 3, Leiden, 461-482).

Tim Penyusun. (2009). Pedoman Kajian Tradisi Lisan (KTL). Jakarta: Asosia Tradisi Lisan (ATL).

MD, Sagiman (2014). http://id.wikipedia.org/wiki/Suku_Betawi, diakses Kamis, 6 Agustus 2014) 